Session 3652

\title{
REDIRECTING ENGINEERING Ph.D. PROGRAMS TO MEET JOB DEMANDS
}

\author{
Merl Baker \\ College of Engineering and Computer Science \\ University of Tennessee at Chattanooga
}

\begin{abstract}
Abstact
Recent articles by John A. Armstrong, "Rethinking the Ph.D." [1] and Phillip A. Griffiths, "Reshaping Graduate Education", [7] prompt faculty and administrators responsible for graduate education to study and implement changes that are needed in our programs. An analogy is drawn between the issues proposed by these articles and deep-rooted problems targeted by Michael Hammer's and Steven Stanton's [10] in the "Reengineering Revolution" and Hammer's and James Champy's justifications for "Reengineering the Corporation" [9]. However, caution must be exercised not to erode the proven process. This alert is well justified by Norman R. Augustine. [2]
\end{abstract}

\section{Arguments for Change}

Armstrong and Griffiths make strong arguments for change in order to meet employer's demands. Phillip Griffiths is Chair of the National Academies', (NAS, NAE, NIM) Committee on Science, Engineering, and Public Policy, (COSEPUP). His article reflects the deliberations of the Committee and the conclusions must not be ignored by academic leaders and employers. Griffiths argues,

$\mathrm{Ph} . \mathrm{D}$. training must change to prepare students for jobs they are likely to find. The U. S. system of graduate education in science and engineering is one of the nation's great strengths. It has served as an international model ---. But changes in the way science and engineering are conducted and funded are exerting stress on the traditional system of graduate education.

John A. Armstrong recently retired as IBM's Vice President for Science and Technology and his article reflects a strong corporate viewpoint. However, this industrial perspective is in good agreement with the COSEPUP report. Change is justified, but how can we change without eroding the quality of the traditional Ph.D?

Norman R. Augustine expresses this concern succinctly.

The seemingly effortless success of American technology, largely the result of university research, appears to have lulled us into the false assumption that the system is self sustaining.

Although in another paper at this conference, the need for change in graduate education is related to the concept of reengineering in industry, I recognize that Dr. Augustine concerns must be carefully calculated before advocating a dramatic restructuring of the macro process.

An increasing number of future Ph.D.s will be performing work which has not been available in the past. Redirecting the process is needed to produce the new types of Ph.D.s expected by the expanding base of present and future customers. If broad customer expectations and demands are not met adequately, many graduates of traditional Ph.D. programs will not find employment. The Nation must have an increasing number of highly-educated scientists and engineers, but their expertise has to be focused on strategic national needs rather than totally on traditional values.

Griffiths' article was based on the COSEPUP report of the National Academies, and emphasized that to meet the expectations of most employers, many graduates have to be trained in broad areas, especially communications, team work, 
and finance. These concepts are now emphasized in master of science programs in engineering management in many universities. A stronger emphasis on design, the practice of engineering, and management is advocated for most graduate programs. These goals are being pursued presently at the masters levels in many graduate programs, but not broadly or significantly at the Ph.D. level.

The exception is at the very few universities offering a Ph.D in engineering management. Perhaps as a start for reengineering $\mathrm{Ph} . \mathrm{D}$. curricula is to increase the number of graduates from engineering-management Ph.D. programs. Graduates are expected to be highly welcomed by employers in the new environment described by Armstrong, Bloustein, and Griffiths.

\section{The Reengineering Concept}

Michael Hammer states that reengineering is clearly an idea whose time has come. Hammer considers reengineering as a revolution and defines it as, "The fundamental rethinking and radical redesign of business processes to achieve dramatic improvements in performance." [8] His performance measures include cost, quality, services, and speed. Reengineering has emerged from the TQM philosophy as a means for improving processes. TQM assumes that the process is basically sound and that necessary continuous incremental improvements can be achieved through a structured approach to problem solving and an unfaltering commitment of informed leaders. However, reengineering digs deeper by challenging the fundamental process and questioning why it should even be sustained.

Most corporations which have embraced the reengineering concept have studied the option of radical restructuring as proposed in Hammer's 1990 article, but most often accept and implement the less-radical modifications required to achieve significant gradual improvements in the macro process $[6,11,12]$.

The traditional Ph.D. process in U. S. universities is an integration of (a) a block of academic courses, (b) literature reports, (c) academic work experiences, and (d) an original basic-research dissertation. Initially in this paper, challenges by respected leaders of the traditional process has been recognized. However, since it has been proven highly successful in most respects the conclusion is that, "radically displacement is unnecessary and ill advised".

In response to Armstrong and Griffiths' deep concerns, significant and tangible incremental changes in the macro process by small sub-processes substitutions are deemed essential to achieve continuous improvements and provide high quality services to customers of all types. Customer demands are changing rapidly and the macro process must be sufficiently flexible to accommodate these promptly and effectively.

This particular ASEE audience is especially interested in graduate education for scientists and engineers, but all Ph.D. programs must be assessed in the context of changing world conditions and job markets, and be altered accordingly. The traditional programs have and will continue to be effective in producing Ph.D.s for academe, national laboratories, and basic research in industry, but the future demands for these traditional graduates will decrease further before a plateau is reached.

However, redirection to achieve adequately the objectives of Armstrong, Griffiths, Bloustein, and others is not simply providing a limited focus on engineering management Ph.D.s only, but more broadly a redirection of the macro process for all technical/scientific curricula/programs to provide options and diversity. Flexibility for all Ph.D programs, even beyond science and engineering, can enable the selective inclusion of a diversity of courses and practices, and if strategically planned substitutions will not erode traditional quality.

\section{A Practice-Oriented Alternative}

The Ph..D. in engineering management offered by a few universities is one approach to a practice-oriented Ph.D, and the number of graduates from these programs should be expanded to meet some of the future needs of employers. However, much broader objectives are deemed most promising and can be achieved by sub-process substitutions. One example is a program which substitutes a high-level design or engineering project, or a complex case study, in industry or a government laboratory for the traditional basic-research dissertation. This substitution would not necessarily require any change in the course work specified. 
While Chancellor of the University of Missouri-Rolla, with the encouragement of regional high-tech employers, I proposed to the engineering faculty a doctor of engineering as an alternative to the Ph.D. Only the departments with an established Ph.D program were to be eligible to offer this option. This restraint was effective in responding to critics that quality would be eroded. The faculty approved the degree after indepth deliberations and it was then submitted to the Board of the University System, about 1970, and approved as a customer oriented doctoral option.

According to Armstrong, increased attention must be paid to research in the so-called strategic areas, those that are most likely to help the Nation achieve its economic or environmental goals. He recognizes that educators consider changes to be delicate. He proposes that instead of cloning their faculties, science and engineering graduate schools should be preparing their Ph.D. students for a variety of possible roles. Although basic research is essential, this collective expertise alone is insufficient for our society to achieve its economic and environmental goals since R\&D represents less than 5 percent of the process by which wealth and jobs are created.

\section{Work Experience Outside of Academe During Ph.D Study}

Adding work experience outside of academe is a viable small process substitution to address contemporary needs. This and a shorter study period to complete the macro process is highly recommended. The internal academic work experience today is too often a repetition of one year's experience rather than a sequence of new and diversified multi-years of experiences.

Armstrong recognizes that the U.S. currently enjoys world leadership in many areas of research and must be careful to preserve this advantage, however, we need to address deficiencies in our national performance in the 95 percent of wealth-creation that is not $\mathrm{R} \& \mathrm{D}$. The substitution of an in-depth report of a high-level design or engineering project, or a carefully structured case study, for the basic research dissertation is not considered radical, but provides a tangible process modification. Griffiths, Bloustein, and Armstrong's arguments support this option along with flexibility in the block of courses undertaken and adding work experiences outside of academe.

\section{Ethics and Public Policy}

Engineers and engineering managers have a strong sense of responsibility to develop products and make decisions that are highly beneficial to society [3],[4]. They also have an admirable propensity to adhere to prescribed ethical codes of the profession. However, the need for a higher level of societal concern and public responsibility is now emerging with increasingly sophisticated high technology products and services. Special courses in graduate curricula are advocated as a third sub process substitution to help engineering managers and engineers develop a better understanding of the role of technology in shaping public policy, and developing a moral-reasoning process. These experiences sharpen their capabilities and sensitivity for decisions to serve better the public interest at the highest possible level.

Masters of Science in Engineering Management curricula strive to combine engineering expertise and management skills so that the conservatism of engineering is given a heavy weight in management decisions if significant risks are involved. Courses in ethics and pubic policy in the curriculum for engineering management, technical engineering masters programs, and restructured $\mathrm{Ph} . \mathrm{D}$. programs are expected to instill in graduates broadly a greater sensitivity to risks, societal values, and a persistence to resist diligently high-risk management decisions not adequately supported technically.

\section{Education, Industrial, and Government Partnerships}

Edward J. Bloustein, President of Rutgers University advocated the second land-grant revolution at the 1987 NSF Conference, "Industrial Science and Technological Innovation", Georgia Institute of Technology. This address recognized at an early date many of the changing needs of employers for Ph.D.s expressed more recently by Armstrong, Griffiths, and others.

In his introduction, Bloustein cited Lincoln's commitment to the economic future of our young nation by his signing into law the Land Grant Act in 1862 which provided for our network of agricultural and mechanical colleges.

Now, [more than] 100 years later, we are witnessing what I have come to think of as the second land-grant movement, the post-industrial land grant revolution. Like the first such revolution, it too, has come swiftly and has 
begun to touch Americans everywhere and every day. Like the first, it too rests on a radical transformation of many of our institutions of learning. Like the first, it too involves a cooperative effort of the federal and state governments, as well as of the private sector of American life. And, like the first, it too involves a new form of technology transfer, anew way of bringing the lessons of the library and the laboratory to bear on the economy of the nation.

Dr. Bloustein offers a challenge to faculty and administrators to respond to new demand in higher education in research, eduction, training, and national involvement. The redirection's of Ph.D. programs proposed in this paper are prompted by changing national priorities and employer needs, and reinforced by recent challenges of a visionary educator for creating essential partnerships. Ph.D. programs must be redirected to promote partnerships focused on strategic national problems if the Nation is to prosper in the highly competitive international marketplace, and if the quality of life for all citizens sustained and enhanced. However, advocacy for redirection must be positive and focused on changing needs and jobs, not additional armament for the war on universities as succinctly described by Dr. Augustine.

\section{Conclusions}

Our graduate programs must be revitalized to meet the changing needs of many students and employers and the strategic priorities of the Nation.

The macro process for Ph.D. programs is proven to be sound, but it must be refined to provide essential diversity and continuous improvement expected by customers with rapidly changing national demands.

Tangible improvements in the macro process must establish programs providing for a greater diversity and matrices defining interdisciplinary focuses. Also, a structure must be formulated to address national strategic issues, ethics, public policy, management, economic and environmental security. Options are advocated to substitute an in-depth report on a real world case study or design project for the traditional basic-research dissertation, work outside of academe, and a greater emphasis on ethics and public policy.

\section{References}

[1] Armstrong, John A. "Rethinking the Ph.D." Issues in Science and Technology, Summer of 1994, University of Texas - Dallas, Dallas, TX.

[2] Augustine, Norman R. "Mindless Violence: America's War On Universities", The Bridge, Vol 25, Number 3, Fall 1995, pp 9-13, National Academy of Engineering, Washington, D. C.

[3] Baker, Merl, "Societal Benefits Expected From Courses In Ethics And Public Policy In Graduate EngineeringManagement Curricula", Proceedings of the 1995 Annual ASEE Conference, Anaheim, California.

[4] Baker, Merl, "Developing The Foundation For Ethical Decision-Making and Minimizing Legal Allegations", Proceeding of the 1994 National Conference of the American Society for Engineering Management, Washington, D, C.

[5] Bloustein, Edward J., "The Second Land-Grant Revolution: Universities In Post-Industrial America", The 1987 NSF Conference, "Industrial Science and Technological Innovation", Georgia Institute of Technology, Atlanta, GA.

[6] Garvin, David A., "Leveraging Processes For Strategic Advantage: A Roundtable ---", Harvard Business Review, September-October, 1995, pp 77-90\$

[7] Griffiths, Phillip, A., "Reshaping Graduate Education”, Issues in_Science and Technology_ Summer of 1995, University of Texas - Dallas, Dallas, TX.

[8] Hammer, Michael, "Reengineering Works: Don’t Automate, Obliterate", Harvard Business Review, July-August, 1990, pp 106-112. Cambridge, MA. 
[9] Hammer, Michael and Charnpy, James, Reengineering then Corporation. Harper Business, New York, 1993.

[10] Hammer, Michael and Stanton, Steven, The Reengineering Revolution. Harper Business, New York, 1995.

[11] Mandrish, Elaine and Shaeffer, Robert, " Results Driven Change: Time to Rewire Reengineering" The

Electricity Journal, August-September, 1995, pp 14-21.

[12] Snyder, Meredith, "Customer Focus-Driven Reengineering in Preparation for a Competitive Electric Utility Market", A Project for the MSEM Program of the University of Tennessee Chattanooga, December 1995.

\section{Brief Biographical Information}

Merl Baker is Professor of Engineering Management at the University of Tennessee at Chattanooga. He holds a BSME from the University of Kentucky and a MSME and Ph.D with a major in mechanical engineering from Purdue University. He has received several professional awards and honors including the Distinguished Alumnus Award from Kentucky and the Distinguished Engineering Alumnus Award from Purdue. Formerly, he served as Executive Director of the University of Kentucky Research Foundation and as Chancellor of the University of Missouri at Rolls. He is active in a number of professionals societies and has published widely in the fields of higher education, engineering management, and productivity with over 100 articles. He is on the national board of the American Society for Engineering Management and is President of the Tennessee Society of Professional Engineers. He was elected a Fellow Member of the American Society For Engineering Education in 1994. 